\section{Frederico Simões Barbosa e a peste}

\author{
Frederico Simões Barbosa and the plague \\ Frederico Simões Barbosa y la peste
}

1 Centro de Pesquisas Aggeu Magalhães, Fundação Oswaldo Cruz, Recife, Brasil.

Correspondência A. Almeida

Centro de Pesquisas Aggeu Magalhães, Fundação Oswaldo Cruz.

Av. Prof. Moraes Rego $s / n$, Recife, PE 50670-420, Brasil. aalmeida@cpqam.fiocruz.br
Frederico Simões Barbosa é sempre lembrado como o parasitologista internacionalmente reconhecido por sua atuação no campo da esquistossomose. Entretanto, graças à sua abrangente formação profissional e humanística, deixou numerosas outras contribuições, algumas desconhecidas ou somente lembradas por uns poucos que tiveram o privilégio de em algum momento participar de suas diversas iniciativas, como foi o caso do Plano Piloto de Peste (PPP), desenvolvido na Chapada do Araripe, no Sertão de Pernambuco de 1966 a 1974.

Os mentores e pilares do PPP foram o Dr. Manoel José Ferreira, diretor do Departamento Nacional de Endemias Rurais (DNERu); Dr. José Rodrigues da Silva, diretor do Instituto Nacional de Endemias Rurais (INERu); e o Dr. Frederico Adolfo Simões Barbosa, diretor do Instituto Aggeu Magalhães (IAM), cuja atuação foi fundamental para a implementação do projeto.

Convém reportar que a peste, mais conhecida como "peste bubônica" ou "peste negra", é uma zoonose primordialmente de roedores transmitida pelas pulgas, causada pela bactéria Yersinia pestis e que pode infectar seres humanos e outros mamíferos.

A peste foi introduzida no Brasil pelo porto de Santos (São Paulo) durante a última pandemia, originada na China, com o primeiro caso humano registrado em outubro de 1899. A partir daí, outras cidades portuárias foram sucessivamente infectadas e em março de 1902 atingiu Pernam-
Alzira Almeida 1

buco. O avô do Dr. Frederico, o médico Adolpho Simões Barbosa, juntamente com outros médicos contemporâneos, contribuiu para a confirmação da existência da praga no Recife.

A infecção foi eliminada dos portos por rigorosas medidas de controle prontamente desencadeadas que, no entanto, não lograram impedir a sua propagação para as cidades do interior e a sua posterior focalização entre os roedores nas áreas rurais na maioria dos estados da Região Nordeste. O advento de novos recursos tecnológicos para o combate aos roedores/hospedeiros, pulgas/vetores e tratamento dos doentes resultou na redução da frequência dos casos humanos e da mortalidade. Infelizmente, o programa de controle foi interrompido e a doença ressurgiu na década de 1960 .

A gravidade da situação forçou o Governo Federal a solicitar o apoio da Organização PanAmericana da Saúde (OPAS) para a vinda de um especialista a fim de elaborar um projeto de pesquisas visando à elucidação da conservação, focalização, epizootização e epidemização da peste no Brasil, com vistas à implementação de atividades eficazes de controle.

A equipe mais renomada, então, era a do Dr. Marcel Baltazard, do Instituto Pasteur de Paris (França) e, após os devidos trâmites, o Ministério da Saúde e a OPAS firmaram em 29 de dezembro de 1964 o Acordo BRZ-0901. O projeto também foi financiado, por intermédio de convênios, pela SUDENE (Superintendência de Desenvolvimen- 
Equipe do Plano Piloto de Peste. Chapada do Araripe, Sertão de Pernambuco em 1966 (Acervo do Serviço de Referência Nacional em Peste).

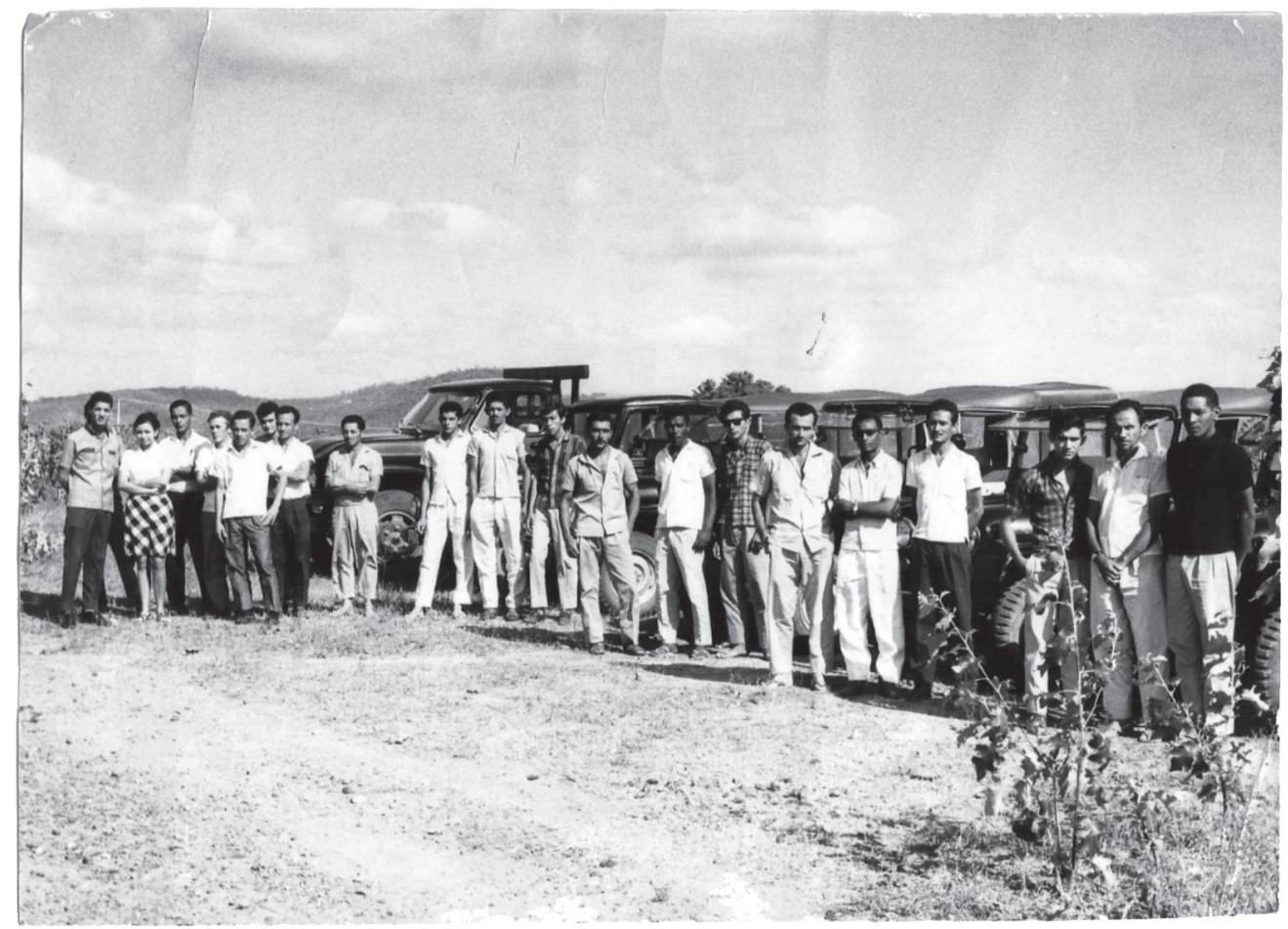

to do Nordeste) e a PAPPE (Unidade de Planificação, Avaliação, Pesquisa e Programas Especiais).

Baltazard chegou ao Recife em maio de 1965 e, após discussões no IAM com o seu diretor Dr. Frederico, e Saul Tavares de Melo, Hipólito Lima Borba e Júlio Brasileiro, médicos do DNERu, realizou em companhia de Celso Arcoverde de Freitas uma viagem de inspeção, que se estendeu até Alagoas, pelas áreas pestígenas da Chapada da Borborema. Em seguida, em companhia de Frederico e Saul, visitou a Chapada do Araripe. Nessa visita, constatou-se a existência de uma escola prática de agricultura em Exu (Pernambuco), construída em 1954 e jamais utilizada, cujas vastas instalações, providas, inclusive, de grupo gerador de eletricidade e adutora de água, poderiam ser utilizadas para a implantação de um laboratório de pesquisas em campo.

Após essas viagens de inspeção, as bases do projeto foram estabelecidas em reunião na sede do INERu, no Rio de Janeiro, com as equipes do DNERu e INERu e os representantes da OPAS, Dr.
Alfredo Norberto Bica, chefe do Departamento de Doenças Transmissíveis, e Dr. Renjifo, chefe da Zona V.

Foi acordado que o IAM, sob a direção do Dr. Frederico, seria o laboratório-sede, responsável pelo aprofundamento dos estudos realizados em campo, assumiria a administração do PPP e trabalharia integradamente com o INERu. Decidiuse, também, que o laboratório para os trabalhos em campo seria instalado em Exu, um dos focos mais ativos no Brasil à época.

Antecipando-se à chegada de um técnico da equipe de Baltazard para o início dos trabalhos, o Dr. Frederico, na condição de executor do projeto, deu andamento aos trâmites burocráticos juntamente com Francisco Arruda, administrador do IAM, e Diva Vitória Cardim, educadora sanitária responsável pelos convênios. O laboratório de peste do Instituto foi reformado e reequipado, e procedeu-se a preparação e aquisição dos insumos necessários ao projeto: ampliação das colônias de cobaias e de camundongos; aquisição de 
material de consumo, equipamentos, tais como as armadilhas para captura de roedores, e uma frota de veículos composta de quatro jipes, um caminhão e uma caminhonete, além do recrutamento e capacitação de recursos humanos.

A equipe foi composta por biologistas (bacharéis em História Natural) - Célio Almeida fez uma capacitação em sistemática de roedores no Museu Nacional, no Rio de Janeiro, com o Dr. J. Moojen; Mauro Fernando Accioly da Silva, que recebeu treinamento em identificação de pulgas; Norma Amorim que aperfeiçoou-se em técnicas sorológicas; Dalva Mello, ainda na graduação, que capacitou-se em bacteriologia. Na época, eu compunha a equipe do Prof. Nelson Chaves como bolsista da Universidade Federal de Pernambuco (UFPE) no Instituto de Nutrição - Departamento de Nutrição Experimental, estava noiva de Célio e tencionava acompanhá-lo na sua ida para Exu. O Dr. Frederico considerou inconcebível o abandono de minha carreira científica para me restringir às atividades domésticas em uma pequena cidade pobre e sem atrativos. Propôs, então, uma vaga na sua equipe, como laboratorista, que eu imediatamente aceitei sendo logo integrada ao projeto.

Fiquei deveras impressionada com a sensibilidade e atenção do Dr. Frederico e eternamente grata pela oportunidade, principalmente por ele não compartilhar do preconceito vigente na época contra o incipiente curso de Nutrição. Para corresponder à sua confiança e fazer frente ao preconceito que havia contra os biologistas e também por muitos funcionários do IAM que não me achavam qualificada para o projeto, empenhei-me para me mostrar capaz e superar qualquer limitação.
A morte súbita do Dr. Rodrigues da Silva, em 1969, determinou profundas alterações na estrutura administrativa do INERu e o Dr. Frederico teve de deixar a chefia do IAM, passando a integrar o programa de controle da esquistossomose da Organização Mundial da Saúde, em Genebra (Suíça).

Seu carisma e sua simplicidade não deixavam transparecer sua vasta cultura, extraordinária competência e experiência. Assim, minha admiração, estima e gratidão pelo Dr. Frederico somente cresceram durante as suas visitas de supervisão dos trabalhos em Exu, bem como posteriormente, nos encontros e eventos científicos e em situações tais como quando se empenhou junto à OPAS, em Brasília, para que me fosse concedida uma bolsa para estágio no Instituto Pasteur de Paris.

O atual Departamento de Microbiologia do Centro de Pesquisas Aggeu Magalhães (Fiocruz Pernambuco) teve origem, em parte, do Laboratório de Peste do IAM e do PPP em Exu, e em 2002, o Serviço, que atuava oficiosamente como referência para a peste desde 1966, foi credenciado como Serviço Nacional de Referência em Peste (SRP) pelo Ministério da Saúde.

Apesar da sua breve atuação no projeto, nunca deixei de associar o PPP ao Dr. Frederico. A semente por ele lançada desenvolveu e frutificou ao longo dos anos. Os trabalhos realizados pela equipe forneceram significativa contribuição ao conhecimento da zoonose no país, muito embora alguns aspectos, 50 anos depois, ainda permaneçam inexplicados, exigindo estudos complementares. A experiência obtida nos estudos de campo também fundamentou o atual Programa de Controle da Peste (PCP) do Brasil. 